\title{
A Detailed Review on Common Causes of Postharvest Loss and Quality Deterioration of Fruits and Vegetables in Ethiopia
}

\author{
Muluneh Bekele Etana \\ Department of Horticulture, College of Agriculture and Veterinary Science, Ambo University, Ambo, Ethiopia \\ Bikila Ollika Fufa \\ Department of Horticulture, College of Agriculture and Veterinary Science, Ambo University, Ambo, Ethiopia \\ Mosissa Chewaka Aga \\ Department of Horticulture, College of Agriculture and Veterinary Science, Ambo University, Ambo, Ethiopia
}

\begin{abstract}
The loss of foods in the post-harvest system is not new; it has always been a problem for mankind. In these days of rapidly enlarging population in the developing countries of the world where food is already short, there is an increasing urgency to do a better job of conserving mankind food supply in order to alleviate hunger and malnutrition. Losses of fruit and vegetables are occurring from the field to the fork and even pre-harvest practices are strongly affects the magnitude of losses that occur at a later stage. Postharvest loss is the issue of food security in many developing countries like Ethiopia and it is the concerns of all people. Severe fruits and vegetables postharvest loss and quality deterioration mainly occurred during harvesting, marketing, transporting, processing and storage which leads to reduction in producers out puts, unavailability of food, malnutrition, effects on the economy of the people and the country. There is high magnitude of loss in fruits and vegetables crops as compared to other due to the nature of the crops. Many scientific studies were reported that numerous causes and the extent of the loss particularly, in fruits and vegetables. This might be because of financial, managerial and technical knowledge limitations in harvesting techniques, storage and cooling facilities in difficult climatic conditions, infrastructure, packaging and marketing systems. In order to minimize these problems, the appropriate agricultural techniques such as the general principles of extending shelf-life of these crops must be put in place. There should be proper management of temperature, humidity and effective methods for preventing these losses. Since most national governments acknowledge that postharvest food losses is complex, therefore, it requires a commitment to an integrated approach, involving numerous organizations, including local communities and groups. As a general, this can be used as a good indication as all concerned bodies should aim for development of effective and efficient policies and strategies to solve existing problems. So the main objective of this review is to find out the concepts and problems of post-harvest food losses in perishable crops.
\end{abstract}

Keywords: Ethiopia, Fruits, Postharvest loss, Quality deterioration, Vegetables

DOI: $10.7176 / \mathrm{FSQM} / 87-01$

Publication date:May $31^{\text {st }} 2019$

\section{Introduction}

Most studies on post-harvest technology have so far concentrated on grains and other durable products, which are stored dry and a substantial technology has been developed to deal with these problems. Less work has been undertaken on the perishable food crops, yet they are of great importance in many parts of the humid and subhumid tropics and contribute the staple carbohydrate portion of the diets in the developing countries. Ethiopia has a wide range of agro-ecological conditions with diverse verities of horticultural crops including temperate, tropical and subtropical crops. There are large numbers of fruits and vegetables that are cultivated for local, national and international markets. They are also crops of great economic importance with a prospect for local consumption, export markets, processing and play great role food security and poverty reduction. They are also important sources of nutrients, minerals and vitamins for human health and wellbeing [12].

These perishable staple foods (fruits and vegetables) are very largely produced from small-scale subsistence level systems and the technologies employed in both production and utilization is usually simple and founded on long established traditional practice. Fruits, vegetables and root crops are living plant parts containing more water, and they continue their living processes after harvest. Fresh fruits and vegetables are crops with high water content and subjected to desiccation and to mechanical injury. Their post-harvest life depends on the rate at which they use up their stored food reserves and their rate of water loss. When food and water reserves are exhausted, the produce dies and decays. So that such perishable commodities need careful handling during harvesting operation and during Postharvest handling so that deterioration of produces is minimized as much as possible during the period between harvest and consumption. There is a report that total postharvest loss of banana as $26.5 \%$ where $56 \%$ of the loss was occurred at the retail level due to rotting before reaching consumers 
in Ethiopia [1]. Besides, Post-harvest loss assessment of fruits and vegetables were conducted in Jimma and the result indicated that there were greater postharvest losses of mango $(35.5 \%)$ and banana (40.0\%) in Jimma town and the postharvest losses and quality deteriorations were mainly attributed to poor handling during transportation and the use of poor marketing structures to sell their fruits and vegetables [2].

Furthermore, severe post-harvest loss and quality deterioration of fruits and vegetables mainly occurred during harvesting followed by marketing, transporting and storage. Poor quality equipment and materials usage caused tremendous mechanical, physiological and pathological damages on fruits and vegetables. Similarly, there is an assessment report in Post-harvest loss of fruits and vegetables in South Wollo and indicated that; poor transportation, storage and unsatisfactory market situation are the main cause for postharvest loss [4].

Generally, producers (farmers), retailers, wholesalers, research institutes and other public and none governmental organizations need to have clear understanding of postharvest loss, causes of postharvest loss and quality deteriorations in fruits and vegetables crops in Ethiopia. Hence, the main objective this paper is to review on the major causes of postharvest loss and quality deterioration of fruits and vegetables in Ethiopia. This can be used as a good indication as all concerned bodies should aim for development of effective and efficient policies and strategies to solve existing problems.

\section{Causes of Postharvest Losses and Deterioration of Fruits and Vegetables}

Ethiopia has a comparative advantage in a number of fruits and vegetables productions because of its favorable weather, cheap labour, proximity to export market such as Europe and Middle East [14]. However, the production of fruit and vegetable is much less advanced than the production of staple grains. Since Postharvest management of fruits and vegetables have not been give satisfactory attention considerable loss occurs at harvest and Postharvest phases and majority of postharvest losses for horticultural produce are difficult to measure [2]. Even though the horticultural sector in Ethiopia is growing there is low and insufficient support for the improvement and reduction of postharvest loss and quality deterioration of horticultural crops were reported [3]. On the other hand, an estimate of 15 to $70 \%$ of postharvest losses of horticultural crops in Ethiopia was reported [8]. Thus, such losses during harvest are a major source of food loss and could be seen from food security and poverty reduction aspects in the country as such losses have direct effect on peoples livelihood and economy of the country as whole. Many researchers reported that the most common causes of postharvest losses such as lack of sorting to eliminate defects before storage and the use of inadequate packaging materials, rough handling and inadequate cooling and temperature maintenance [7].

\subsection{Nature of the Crops}

Ethiopia is one of the developing countries in East Africa. Tropical, subtropical and temperate fruits and vegetables have been grown in the country. The country has comparative advantage in a number of horticultural commodities due to its favorable climate, high domestic demand and cheap labor. Majority of production operations conducted by small-scale farmers and supplied for near markets for sale. Variety of fruits and vegetables cultivated but not all produces reach consumers.

Fruit and vegetable crops contain relatively high moisture content, large in size and soft texture as compared to cereals and legumes and marketing immediately after harvesting is advantageous. This is because of the fact that fruits and vegetables are alive and can loss water through respiration and transpiration. In addition, researchers reported that vegetables are characterized by high metabolic activities and known to have short storage life [5]. The perishability nature and hugeness makes horticultural crops difficult to manage easily during postharvest period unlike that of dry grains $[6,20]$.

They need careful handling and in the absence of appropriate handling and optimum environmental conditions their storability affected and the chance of loss enhanced. Thus, leafy vegetables are more affected than root crops and fruits produce and great care has to be taken to reduce rate of deterioration during harvesting, transporting, storage and marketing.

\subsection{Disease and pest problem}

Due to the impact of disease and pest at production level, the damaged, bruised and unhealthy parts of fruits and vegetables are the major causes for postharvest loss and quality deterioration. Especially there is a report that the influence of cutworm while the crops are at field level is common for fruit crops like tomato. The major insect and mite pests of tomato include African bollworm, potato tuber moth and tomato leaf miner/fruit borer, whiteflies and spider mites.

\subsection{Marketing facilities Problem}

Fruits and vegetables products in Ethiopia are mainly produced by smallholder farms and most of the farmers sell their products on nearby market and a few sell both on farm and in nearby market such that the marketing condition is unsatisfactory and discouraging [4]. The reasons for unsatisfactory market condition indicated that 
higher supply of the produce at a time, middle men exploitation, and products sell on farm and on the nearby market.

There is research report on major postharvest loss assessment of fruits and vegetables at Jimma that elaborated presence of highest percentage loss for fruits during marketing that in Seka Chekorsa town as the fruits were sold in the open space of road sides being exposed to sun [2]. Similarly other researchers reported that, lack of market to absorb the production, large number of middlemen in the marketing system, absence of marketing institutions safeguarding farmers' interest and rights over their marketable produces, lack of coordination among producers to increase their bargaining power and imperfect pricing system of traders as major problems to producers [8].

\subsection{Lack of credit/financial service}

Limited Credit service for horticulture sector in Ethiopia and lack of credit provider especially on horticultural crops postharvest handling to maintain the quality of the produce and to extend the shelf life of the produces were indicated as constraints in country. On the other hand most of the respondents' in many research reports in Ethiopia indicated that the reasons for not participating in credit market were related to religion.

\subsection{Packaging, Transportation and Storage problem}

Use clean, smooth and ventilated containers for packaging. This is a very important factor in cutting down losses in these crops during harvesting, transportation marketing and storage. Use containers that are appropriate to the crop. There is a research report of only $31.1 \%$ of shops that stored physically injured and spoiled fruits separately in the assessment of fruit management that conducted in Gondar town [12]. Similarly the transportation system in postharvest handling of horticultural produces had done loading one over the others which subjects the products to injury, damage and finally shortens shelf life of the produces. Mixed loads of bulk commodity is again a serious concern as the produces have different responses to temperature, transpiration, dehydration, ethylene are transported together which all together affect durability of the commodities through enhancing physiological, mechanical, biological and chemical losses. According to the research reports, potato postharvest loss of 3.98\% at transport and $10.08 \%$ at storage reported at Jeldu districts of West Shewa Zone, Ethiopia [8].

In adequate packaging material, transportation and lack of appropriate storage facility were reported as factor of postharvest loss and quality deteriorations of fruits and vegetables in Ethiopia [5, 10, 11, 13, 19]. On the other hand scientists described that absence of farm storage facility and proper packing station results in the perishable produce being marketed immediately after harvesting without primary processing and adequate packaging [9, 18]. Different containers such as wooden box, baskets, plastic materials and sacks used in collecting various produces from farms during harvesting with inadequate handling that enhances level of produce damage. Packages need to be vented yet be sturdy enough to prevent structural change. If produce is packed for ease of handling, waxed cartons, wooden crates or rigid plastic containers are preferable to bags or open baskets, since bags and baskets provide no protection to the produce when stacked. Not packing, over filling of containers and mixing unlike produces was major problem in postharvest. Majority of traders store injured and unhealthy produce together with normal ones and finally come across losses.

\subsection{Processing and value addition Problem}

When conditions are not suitable for storage or immediate marketing of fresh produce, many horticultural crops can be processed using simple technologies. There are many processing methods that can be used by small-scale handlers, including drying, fermenting, canning, freezing, preserving and juicing. Fruits and vegetables can all be dried and stored for use or sale in the future. Fermentation is popular throughout the world as a food preservation method. Fruits and vegetables can be canned or frozen, and fruits are often preserved in sugar or juice [23].

Processed products must be packaged and stored properly in order to achieve their potential shelf life of up to one year. Dried products must be packaged in air-tight containers (glass or plastic bottles or sealed plastic bags). Canned and bottled products must be adequately heat processed using high quality containers that provide good seals. Dried and canned or bottled products are best stored in a cool, dark place [22, 24].

\section{Summary and Conclusions}

Postharvest losses and quality deteriorations occur from the field to the fork and even pre-harvest practices and decisions are strongly affect the magnitude of losses that occur at a later stage. Growers should harvest at the appropriate stage and time, sort carefully, keep the product in shade to minimize harvest unnecessarily heat, wash harvest containers as much as possible, use appropriate transport means so as to reduce injuries. Losses at retailers and whole sellers should be minimized. This can also be obtained by using appropriate storage facility. Therefore, educational and training programs could be seen as one of the best strategies to deal with Postharvest 
loss minimization both in the field and during storage. Development agents, extension workers and horticulturists should have enough understanding the issue and impacts of Postharvest loss and should participate in training farmers to take care in controlling losses.

Generally, with the assistant of government programs related to post-harvest handling, and government extension services, postharvest technology from other countries could be adapted for economically important perishable horticultural crops.

\section{Conflict of interest}

Regarding the publication of this manuscript, there is no any conflict of interest.

\section{Acknowledgements}

We would heartedly like to thank and praise the Lord Almighty God in giving us strength and wellbeing to successfully complete the study. We also want to thanks for all Ambo University horticulture department staff for all their help and moral support. Finally, all the reference materials used in this paper are dully acknowledged.

\section{References}

1. Mulualem AM, Jema H, Kebede W, Amare A (2015) Determinants of Postharvest Banana Loss in the Marketing Chain of Central Ethiopia. Food Science and Quality Management, 37: 52-63.

2. Adugna D, Gerba D, Diriba B, Kassaye T (2011) Identification of major causes of postharvest losses among selected fruits in jimma for proffering veritable solutions. International Journal of Current Research, 3(11).

3. Mohammed K, Afework B (2016) Post-harvest loss and quality deterioration of horticultural crops in Dire Dawa Region, Ethiopia. J Saudi Society of Agricultural Sciences, 1-9.

4. Seid H, Hassen B, Yitbarek WH (2013) Postharvest Loss Assessment of Commercial Horticultural Crops in South Wollo, Ethiopia "Challenges and Opportunities". Food Science and Quality Management, 17: 34-39.

5. Hagos DG (2014) Supply Chain Management (SCM) Approach to Reduce Post-harvest Losses with Special Emphasis on Cabbage Supply from Akaki to Addis Ababa. A Thesis Submitted to the School of Graduate Studies of Addis Ababa University in Partial Fulfillment of the Requirement for the Degree of Master of Science in Civil Engineering (Road and Transport Engineering).

6. Gebru H, Belew D (2015) Extent, Causes and Reduction Strategies of Postharvest Losses of Fresh Fruits and Vegetables - A Review. Journal of Biology, Agriculture and Healthcare, 5(5).

7. Kitinoja L, Kader AA (2002) Small-Scale Postharvest Handling Practices: A Manual for Horticultural Crops $\left(4^{\text {th }}\right.$ edn) woodland: University of California, Davis.

8. Misrak U, Mulugeta N, Thangavel S, Girma G (2014) Assessment of Post-harvest Losses of Ware Potatoes (Solanum tuberosum 1.) in Chelia and Jeldu districts of West Shewa, Ethiopia. International Journal of Research in Science, 1(1):16-29.

9. Faris A (2016) Review on Avocado Value Chain in Ethiopia. Industrial Engineering Letters, 6(3):33-40.

10. Atanda SA, Pessu PO, Agoda S, Isong I, Ikotun I (2011) The concepts and problems of post-harvest food losses in perishable crops. African Journal of Food Science, 5(11).

11. Zenebe W, Ali M, Derbew B, Zekarias S, Adam B (2015)

12. Asmaru G, Samuel S, Subramanian C (2013) Assessment of Fruit Management in Gondar town Markets of North Western, Ethiopia. Global Journal of Biology, Agriculture and Health science, 2(4): 4-8.

13. Assessment of Banana Postharvest Handling Practices and Losses in Ethiopia. Journal of Biology, Agriculture and Healthcare, 5(17).

14. RUEL, M. T., MINOT, N. \& SMITH, L. 2005. Patterns and determinants of fruit and vegetable consumption in sub-Saharan Africa: a multicountry comparison, WHO Geneva.

15. CSA, Central Statistical Ageny, www.csa.gov Fruit and vegetable cultivation in Ethiopia, 2014-08-10,

16. WORLD BANK, W. 2010. Missing Food: The Case of Postharvest Grain Losses in Sub-Saharan Africa.

17. HODGES, R. J., BUZBY, J. C. \& BENNETT, B. 2011. Postharvest losses and waste in developed and less developed countries: opportunities to improve resource use. The Journal of Agricultural Science, 149, 37-45.

18. RIGG, J., BEBBINGTON, A., GOUGH, K. V., BRYCESON, D. F., AGERGAARD, J., FOLD, N. \& TACOLI, C. 2009. The World Development Report 2009 'reshapes economic geography': geographical reflections. Transactions of the Institute of British Geographers, 34, 128-136.

19. DAVIS, J. C. 1980. Agriculture and transportation: a positive impact, in: increasing understanding of public problems and policies. 51-58.

20. FAO 2012. Global initiative on food loss and waste reduction.

21. VAN GOGH, J. \& ARAMYAN, L. Reducing postharves food losses in developing economies by using a Network of Excellence as an intervention tool. Proceedings of the IFAMA 2014 Symposium Proceedings' People Feed the World', 2014.

22. BOURNE, M. 1977. Post harvest food losses-the neglected dimension in increasing the world food supply. 
23. Campbell-Platt, G. 1987. Fermented Foods of the World: Dictionary and Guide. Stonam, Massachussetts: Butterworth Heineman.

24. Bills, J. and Bills, S. 1974. Home Food Dehydrating. Bountiful, Utah : Horizon Publishers 